\title{
INTRODUÇÃO - A PRIMEIRA REUNIÃO INTERNACIONAL DE TEORIA ARQUEOLÓGICA NA AMÉRICA DO SUL: QUESTÕES E DEBATES
}

\author{
Pedro Paulo A. Funari* \\ Eduardo Góes Neves** \\ Irina Podgorny***
}

\section{Problemas de arqueologias sem problemas}

É sintomático que um encontro como o de Vitória tenha ocorrido em um congresso de Antropologia realizado na capital de um estado, como o Espírito Santo, com pequena tradição de pesquisa em Arqueologia. Tudo isso num país, o Brasil, que, ao contrário de outras nações latino-americanas, jamais produziu trabalhos importantes no que se refere à teoria em Arqueologia pré-histórica. Talvez, não por coincidência, percebemos que um espaço para a discussão de algumas questões teóricas e metodológicas relevantes para a arqueologia brasileira e sul-americana devesse ser procurado fora dos caminhos habitualmente apresentados pela arqueologia nacional. Acreditávamos, então, e o sucesso do evento confirma de certa maneira essa crença, que, agindo desse modo, estaríamos criando condições para o debate franco e aberto.

Não é obra do acaso, ou de um certo viés anglófono, que a única referência feita à arqueologia brasileira na mais completa obra produzida sobre a história do pensamento arqueológico (Trigger 1989) diga respeito aos usos racistas feitos pelas ciências antropológicas no início do século $\mathrm{XX}$, neste caso, por Hermann von Ihering, antigo diretor do Museu Paulista. Com pouquíssimas exceções, a arqueologia brasileira é irrelevante. Irrelevante no contexto internacional, porque pouco produz

(*) Instituto de Filosofia e Ciências Humanas da Universidade de Campinas-UNICAMP, São Paulo, Brasil.

$\left({ }^{* *}\right)$ Museu de Arqueologia e Etnologia da Universidade de São Paulo, Brasil.

(***) Pesquisadora do CONICET, Museu de La Plata, Universidade de La Plata, Argentina. que tenha impacto teórico ou empírico e irrelevante para os brasileiros, já que é incapaz de prover quadros orgânicos, mesmo que provisórios, de nossa história pré-colonial. Exceções a essa regra são os trabalhos de Prous (1992), nossa síntese mais completa; Brochado (1984), nossa síntese mais genial e Wüst (1990), nossa síntese mais sistemática.

Não é por acaso que os três arqueólogos acima citados tenham tido, em algum momento de sua formação, a possibilidade de estudar e trabalhar em centros de produção de conhecimento em Arqueologia localizados em outros continentes. Se tal possibilidade não se constitui, isoladamente, como a garantia de acesso a uma formação acadêmica mais qualificada, ela garantia, no período que, por caso ou não, coincidiu com a ditadura militar, a possibilidade de aquisição, aos mais curiosos ou criativos, de uma formação teórica e prática diferente da camisa-de-força imposta pelo culturalismo histórico do Programa Nacional de Pesquisas Arqueológicas.

Exemplos como os acima indicam, então, que nossa irrelevância deve estar diretamente relacionada a nosso provincianismo. Pouco participamos de reuniões internacionais e, com exceção dos colegas do sul do país, poucos contatos estabelecemos com nossos vizinhos sul-americanos. Lemos pouco periódicos ou livros estrangeiros e neles publicamos menos ainda. Desse provincianismo só se pode esperar consequiências negativas: a constituição de feudos intocáveis; fossilização metodológica; a desatualização teórica e, a pior de todas, o pavor ao debate.

Os trabalhos acima citados, as obras de Brochado e Wüst têm outra característica comum que os destaca no quadro nacional: uma combinação bem dosada entre teoria e prática. Os casos de Brochado e 
FUNARI, P.P.A.; NEVES, E.G.; PODGORNY, I. Introdução - a primeira reunião internacional de teoria arqueológica na América do Sul: questões e debates. Rev. do Museu de Arqueologia e Etnologia, São Paulo, Suplemento 3: 1-12, 1999.

Wüst são exemplares porque mostram como um corpo de dados empíricos - obtidos pela própria autora, no caso de Wüst, obtidos por outros autores, no caso de Brochado - podem ser mobilizados no encaminhamento de problemas de pesquisa bem estabelecidos. No caso de Wüst, o problema se constituía no entendimento do processo de formação das sociedades Bororo documentadas histórica e etnograficamente; no caso de Brochado, o problema - mais ambicioso - era o entendimento do processo de expansão de populações falantes de línguas da família Tupi-guarani. Não por coincidência, esses trabalhos contribuem para a construção de uma história indígena pré-colonial, o que é uma vocação natural da arqueologia brasileira, e é disso que resulta sua relevância. Nesse sentido, importa menos a veracidade de seus modelos, e mais o fato de apresentarem hipóteses testáveis. Ao propor hipóteses testáveis, esses trabalhos estabelecem a possibilidade de diálogo científico, realizado através do teste, que é uma condição fundamental para a superação do provincianismo. O modelo de Brochado é particularmente generoso no que se refere a esse aspecto porque apresenta expectativas cronológicas, geográficas e formais para uma boa parte do registro arqueológico dos sítios cerâmicos do Brasil. Em outras palavras, ele propôs um quadro sintético completo ainda sem par para a arqueologia brasileira. Trabalhos recentes realizados na Amazônia central (Heckenberger et al. 1998) oferecem uma crítica a alguns aspectos desse modelo geral, o que atesta sua vitalidade.

Ao provincianismo, deve-se acrescentar a falta de problemas de pesquisa bem definidos e testáveis na raiz de nossa irrelevância. É, assim, no mínimo, com preocupação que se deve observar a proliferação dos trabalhos de arqueologia de salvamento pelo país, já que, normalmente, seus resultados não são publicados e os problemas, quando presentes, dizem respeito normalmente apenas ao cronograma das obras. Infelizmente, as más condições de financiamento à pesquisa no país tendem a contribuir para o fortalecimento desse quadro.

O encontro de Vitória foi importante para quem dele participou, ou acompanhou, porque reuniu pesquisadores com formações, idades e nacionalidades diferentes para a discussão de alguns problemas relevantes para a arqueologia brasileira e sulamericana. Apesar do título, justiça deve ser feita. Os arqueólogos latino-americanos presentes eram, com exceção do mexicano Bernd Beyer, todos argentinos e brasileiros. Isso, sem dúvida, representa um viés, já que a maioria dos grandes teóricos da chamada Arqueologia Social latino-americana é composta por arqueólogos que não da Argentina ou Brasil. É de se esperar que o próximo encontro, previsto para o ano 2.000, em Olavarría, na Argentina, possa incluir mais arqueólogos de outros países latino-americanos.

Argentina e Brasil, no entanto, são países com problemas parecidos no que se refere às relações estabelecidas entre suas populações contemporâneas e seus patrimônios arqueológicos. Ao contrário do México ou do Peru, a história de ambos os países tem sido construída a partir do marco cronológico constituído pelo início da colonização européia. A Arqueologia não foi, nesses casos, utilizada como elemento para a construção, que é sempre ideológica, de parâmetros de nacionalidade, já que esses parâmetros são, geralmente, eurocêntricos. Por outro lado, as populações indígenas que ocupavam o que são atualmente as áreas mais ricas desses países -as neo-Europas no sentido de Alfred Crosby (1986) - foram total ou parcialmente extintas. É, então, através da atribuição de significados às paisagens atualmente reocupadas pelas populações de origem africana, européia ou mestiça nessas nações que vínculos com o passado pré-colonial podem ser estabelecidos.

Temas referentes a essa questão geral foram discutidos de diferentes maneiras em Vitória: desde aspectos relativos ao tratamento do patrimônio arqueológico, passando pelo estudo dos diversos significados da paisagem, a identificação de marcadores de etnicidade no passado e a própria história da Arqueologia, sem contar as contribuições de caráter mais filosófico. O encontro de Vitória procurou, então, instaurar uma prática de discussão teórica em Arqueologia quase inédita entre nós, no entanto, importante no quadro da Arqueologia contemporânea, como será visto a seguir. Com isso, poderá ter feito uma pequena contribuição para a superação do provincianismo e da falta de problemas que caracterizam a arqueologia brasileira.

\section{A teoria arqueológica nos encontros acadêmicos}

A História das reuniões específicas sobre teoria arqueológica pode iniciar-se na década de 1980 , ainda que seja importante assinalar que as discussões de ordem conceitual têm estado sempre pre- 
FUNARI, P.P.A.; NEVES, E.G.; PODGORNY, I. Introdução - a primeira reunião internacional de teoria arqueológica na América do Sul: questões e debates. Rev. do Museu de Arqueologia e Etnologia, São Paulo, Suplemento 3: 1-12, 1999.

sentes na prática da disciplina (Podgorny m.s.), mesmo nos países pouco propensos à teoria (Härke 1998). Recordemos que os agora consagrados e internacionalizados TAGs (Theoretical Archaeology Group) se reuniram pela primeira vez apenas na década de 1980. Os TAGs, assim, constituíramse como um modelo a ser seguido em outros países, como os TAGs na Alemanha e a Reunião de Arqueologia Teórica, realizada em Santiago de Compostela, na Galícia, Espanha, em 1992, e ambas as iniciativas, destaquemos, foram empreendidas por arqueólogos que realizaram parte de seus estudos em Cambridge. Os primeiros TAGs, por outro lado, devem ser situados no clima do campo acadêmico da Arqueologia britânica daquela época, ou seja, sob a insígnia da ruptura com a Arqueologia "processual" (New Archaeology), de matriz norte-americana.

Em 1986, a Cambridge University Press publicava Reading the Past, de Ian Hodder, que já apresentava a corrente "pós-processual" como uma tendência já consolidada e em crescimento (Hodder 1986). Naquele mesmo ano, realizava-se, em Southampton, o Primeiro Congresso Mundial de Arqueologia (WAC1), organizado também com uma clara vontade de reflexão sobre a prática arqueológica. Antes disso, o mesmo Hodder, sempre em Cambridge, havia incluído a reflexão sobre a relação entre a objetividade e a sociedade, a crítica ao passado como mercadoria e as percepções populares sobre a Arqueologia e o passado, na GrãBretanha (Hodder et al. 1985; Stone 1986). Em 1987, Hodder escrevia o prólogo do livro de Michael Shanks e Christopher Tilley (1987) celebrando, como novidade, o nascimento de "uma nova era de uma disciplina informada na Filosofia e com consciência crítica" (Hodder 1987, in Shanks e Tilley 1987: prefácio). "Não há dúvida que, tanto em Cambridge como no WAC, o tema era a ruptura": enquanto as novas gerações de Cambridge discutiam e se livravam da herança da New Archaeology, ${ }^{1}$ o WAC nascia para diferenciar-se da União Internacional de Ciências Pré e Proto Históricas (UISPP), a organização líder na Europa. O programa de WAC1 refletia estas tendências e as introduzia no campo acadêmico internacional (Podgorny 1996).

(1) As idéias expostas sobre o papel do WAC, no sentido de recuperar, para a arqueologia britânica, a hegemonia perdida no campo acadêmico anglo-saxão, refletem a troca de idéias entre os autores também com Norberto Luiz Guarinello.
O WAC surgiu em 1986 como um encontro alternativo àqueles tradicionalmente estabelecidos. Assim, o que deveria ser o $11^{\circ}$ Congresso da UISPP transformou-se no WAC. Como Ucko (1987) descreveu, este foi um longo e árduo caminho. A dificuldade surgiu ao incorporar o boicote cultural declarado à Namíbia e à África do Sul, por causa da política do Apartheid, como um critério para a admissão como membro do Congresso, impedindo-se a participação dos arqueólogos ligados a instituições dos países que praticavam a política de discriminação racial de Estado. Ucko (1987) levantou a oposição como uma opção entre "liberdade acadêmica e apartheid". Kohl (1988) assinalou que tal polarização criava uma falsa dicotomia entre um regime condenável e as regras do campo intelectual. Por outro lado, este critério supunha uma sanção acadêmica internacional para com as políticas nacionais e não para as práticas acadêmicas, já que se pretendia condenar, não tanto os arqueólogos por sua adesão, ou não, ao "regime de Pretória", como, principalmente, o próprio regime racista, assumindo uma concepção da prática acadêmica como ferramenta política. Além da assimetria contida nesta ação, este ato adquiria sentido como criador de uma organização arqueológica que correspondia a outros princípios e se dirigia a outro público. Da reunião de Southampton, em 1986, resultou que, pela primeira vez, representantes de povos e organizações indígenas discutissem com os arqueólogos em um encontro de dimensão internacional. Ademais, tornou-se um verdadeiro marco para a História da Arqueologia, na medida em que WAC1 incorporou, dentro do campo epistêmico da disciplina, uma série de temas e problemas até então excluídos, ou tidos, senza pensiero, como inexistentes, como o questionamento da objetividade, a problemática das relações de gênero, o caráter público da Arqueologia, a ética e as próprias relações de poder no interior da disciplina.

Já em 1987, o WAC institucionalizou-se como organização, definindo-se, estatutariamente, como:

"An international non profit making organisation concerned with all aspects of archaeological theory and practice. Its main emphasis is on academic issues and questions which benefit from a widely oriented and comparative approach. It attempts to bridge the disciplinary division of the past into chronological periods and to avoid exclusive, particularistic concerns.

WAC is based on the explicit recognition of the historical and social role, and the political con- 
FUNARI, P.P.A.; NEVES, E.G.; PODGORNY, I. Introdução - a primeira reunião internacional de teoria arqueológica na América do Sul: questões e debates. Rev. do Museu de Arqueologia e Etnologia, São Paulo, Suplemento 3: 1-12, 1999.

text, of the archaeological enquiry, of archaeological organisations, and of archaeological interpretation" (WAB 1991, 5: 133, grifo nosso).

O enfoque comparativo levava a discussão para além do campo da empiria, para os problemas teóricos e conceituais. Igualmente, o reconhecimento do contexto político da prática e da interpretação arqueológicas rompia, assim, com as doutrinas e valores da New Archaeology que, ainda que questionadas por alguns de seus epígonos marginais - entre outros, por Gándara (1982), no México, Kohl $(1981 ; 1985)$ e Gilman, nos Estados Unidos, Trigger (1980), no Canadá e Ucko (1986) na Austrália - continuavam como dominantes no panorama hegemônico mundial, anglo-saxão. A necessidade de uma discussão teórica era, por sua parte, alheia à mais empírica Arqueologia do continente europeu que dominava a UISPP (Ruiz Zapatero 1993). A partir deste momento, na Grã-Bretanha, pareceram perfilar-se dois polos: um em Cambridge, com o programa pós-processual, ligado à interpretação e às discussões epistemológicas pós-modernas; o outro, em Southampton, com um perfil marcado pelo programa do WAC, com sua ênfase nas implicações políticas, relativas ao campo do poder, da disciplina arqueológica e, como decorrência, com um destaque para o relacionamento entre as arqueologias centrais e periféricas, da Ásia, África e América Latina. ${ }^{2}$ Por outro lado, destaquemos que, em termos europeus, os TAGs e o surgimento daEuropean Association of Archaeologists, em princípios da década de 1990, ocuparam parte do espaço que o WAC queria para si, sendo que tanto as preocupações teóricas quanto políticas desses empreendimentos acadêmicos não podem ser desvencilhados das discussões surgidas no WAC. Nos Estados Unidos, por sua parte, a filiação ao WAC continuou limitada, o que talvez se deva aos poucos contatos entre a arqueologia

(2) Isto não significa que os arqueólogos britânicos se tenham alinhado, de forma uniforme, a qualquer dos dois programas. Ao contrário, a resistência a ambos foi, em muitos casos, mais frequiente do que sua aceitação. Com efeito, como toda corrente que pretende consolidar-se, constrói-se a partir de uma retórica de ruptura, de nova era e de projeto para o futuro. Convém recordar, contudo, que a retórica de fundação não se confunde com a sua aceitação como projeto. Por fim, deve-se lembrar que os dois campos mencionados foram constituídos, às vezes, pelos mesmos indivíduos e podem ambos ser opostos à Arqueologia empirista e apolítica dominante. norte-americana mainstream e as discussões epistemológicas das humanidades. ${ }^{3}$

No contexto do WAC, graças a uma série de livros, One World Archaeology, que seguiu ao primeiro encontro, temas inovadores e revolucionários foram tratados, como a Educação, os conflitos étnicos gerados pela dimensões políticas da prática da Arqueologia, e passaram a se incorporar aos programas de pesquisa arqueológica. Tais questões foram incluídas no Primeiro Intercongresso (Vermillion 1989) sobre ética arqueológica e o tratamento da morte, sobre a História Política da Arqueologia no WAC2 (Barquisimeto, Venezuela 1990) e no Segundo Intercongresso (Mombassa 1993), sobre as origens do urbanismo na África. O WAC3, em Nova Delhi (1994), além de ter gerado uma crise importante na organização, constituiu um bom indício da institucionalização dos temas que, em 1986, apenas começavam a emergir. De fato, aquilo que em Southampton aparecia como um esboço de pesquisa ou de novas práticas da Arqueologia, mostrava-se bem estruturado em 1994, como atestam os papers pré-circulados de WAC3: os anos transcorridos haviam testemunhado teses de doutoramento, criação de postos de trabalho e formação de estudantes e estudiosos destas novas tendências.

Em outro sentido, o WAC propôs-se uma visão "verdadeiramente mundial" Destaque-se que a escolha dos lugares para as reuniões procurou colocar no mapa acadêmico locais pouco habituais para encontros internacionais, com o objetivo explícito de decentrar o foco e fazer com que aparecessem aos olhos da arqueologia euro-americana. O mesmo pode-se afirmar dos títulos dos livros da série One World Archaeology. Deste ponto de vista, o WAC poderia definir-se como uma organização por meio da qual certos problemas de ordem aparentemente local, regional ou nacional foram submetidos à visão dos lugares que se outorgavam o direito de levantar e definir os motivos de relevância universal. A universalidade da

(3) Naturalmente, as muitas exceções confirmam a regra. De fato, questões como o repatriamento (Zimmerman), o viés étnico (Blakey) e de classe (Orser), para citar apenas alguns, foram levantadas, em escala mundial, por arqueólogos americanos envolvidos no WAC. Já no início da década de 1960, Binford reclamava que os arqueólogos americanos eram pouco propensos à teoria (cf. Funari 1988). 
FUNARI, P.P.A.; NEVES, E.G.; PODGORNY, I. Introdução - a primeira reunião internacional de teoria arqueológica na América do Sul: questōes e debates. Rev. do Museu de Arqueologia e Etnologia, São Paulo, Suplemento 3: 1-12, 1999.

ciência, presente no próprio nome do WAC, ${ }^{4}$ define a especificidade do WAC que reside em ter sido a primeira organização arqueológica internacional com uma marcada vocação inclusiva dos então existentes Segundo e Terceiro Mundos (Podgorny 1996). Em meados da década de 1980, um corpo internacional dirigido por uma maioria de arqueólogos europeus de fala inglesa ou francesa e ligado a centros consagrados tornava-se insuficiente para representar a humanidade. Os novos estatutos do WAC - adotados em setembro de 1990, em Barquisimeto (cf. WAB 5: 133-138) - foram elaborados quase por oposição a esta situação então denunciada como injusta: o planeta foi dividido em quatorze regiões, cada uma representada por um representante sênior e outro júnior, eleito por sua zona. Incorporava-se, pois, a periferia, as mulheres, os jovens, os não ocidentais e os representantes dos povos indígenas. Com estas bases, constituiu-se o Comitê Executivo do WAC, cuja primeira reunião realizou-se durante o Primeiro Intercongresso, coetaneamente ao aparecimento dos livros da série One World Archaeology.

Outro elemento a levar em conta é que o nascimento do WAC deu-se em um contexto diverso do atual. Três anos após o encontro de Southampton, a queda do Muro de Berlim foi o marco do início de uma configuração política internacional que ainda surpreende a quem viveu o quotidiano da Guerra Fria e, em nosso caso sul-americano, das ditaduras fascistas aliadas do Pentágono. Levar adiante um novo fórum nestas circunstâncias complicava-se, não apenas pelas mudanças nos mapas, com o desaparecimento do "Segundo Mundo", mas também porque os conflitos se moviam para lugares cujos nomes eram pouco visíveis até então. Além de análises específicas sobre o fim da União Soviética, esta nova situação deu origem a uma abundante literatura sobre os nacionalismos e particularismos culturais e/ou étnicos. Na Inglaterra, por exemplo, os estudos a respeito têm sido muito freqüentes, tanto a partir da New Left (Hobsbawn 1990, Hobsbawn e Ranger 1983) como a crítica cultural (Colls e Dodd 1986). Neles, demonstra-se a construção histórica das identidades

(4) World, originária de *wer, homem, e *aldh, idade, significa, em inglês e à diferença de Mundo, "a humanidade", "sociedade". Não se perca, pois o sabor humanista de world em WAC, mal traduzido por "mundial" nacionais e/ou grupais, pelo processo de invenção das tradições. Na esteira desta consciência, os arqueólogos começaram a analisar a História da sua disciplina em relação ao nacionalismo (Kohl e Fawcett 1995, Jones 1997), levando, em alguns casos, esta crítica a um subjetivismo extremado (Hodder et al. 1995, Podgorny (no prelo), Tilley 1991).

Desde sua fundação, o WAC pretendeu erigirse como uma instituição não neutra no tratamento de determinados temas que estiveram envolvidos, de algum modo, com a prática arqueológica. É verdade que nem os temas nem as maneiras foram bem definidas mas, pode afirmar-se que o consenso se estabelecia em torno dos direitos humanos, da defesa das minorias e do questionamento da visão ocidental hegemônica. À diferença de uma visão pós-moderna enunciada a partir de Cambridge, a perspectiva cunhada em Southampton tinha certas expectativas de intervenção na realidade, pelo menos na realidade entendida como o contexto extraacadêmico. No WAC, assim, a discussão teórica tornou-se quase sinônimo de abrir a produção de teoria às vozes dos excluídos. World Archaeology talvez pudesse ser traduzida, em nossos vernáculos de origem latina, por uma Arqueologia da Humanidade, cuja diversidade não pode ser obliterada.

\section{Teoria e política}

Aqui, chegamos a um problema que cremos ser central: no contexto das discussões metropolitanas, a inclusão das vozes excluídas parece só ser possível por meio de uma equiparação entre a teoria arqueológica e as práticas políticas. Seja pelo recurso a uma pretendida construção de identidades (acadêmica e/ou cultural), seja pela análise da produção da chamada periferia, a teoria aparece ligada à denúncia de situações de dominação imperial ou de condicionamento direto entre contexto social e produção intelectual. Neste sentido, a teoria encontra-se atada a um destino de pouca autonomia, subsidiário. É certo que, no campo intelectual periférico, por causa de uma autonomia não de todo conseguida, as intromissões da política podem detectar-se com maior facilidade, ainda que isto não explique, por si só, seu funcionamento.

O chamamento do WAC reproduz, em certo sentido, esse lugar: é uma análise externa o que leva a propor-se uma Arqueologia verdadeiramente mundial, enquanto os problemas internos da dis- 
FUNARI, P.P.A.; NEVES, E.G.; PODGORNY, I. Introdução - a primeira reunião internacional de teoria arqueológica na América do Sul: questões e debates. Rev. do Museu de Arqueologia e Etnologia, São Paulo, Suplemento 3: 1-12, 1999.

ciplina ficam restritos ao mundo de um empirismo pouco interessante. Neste contexto, os dados e as evidências arqueológicos só adquirem sentido se permitem demonstrar que sua interpretação resulta do viés político da prática científica periférica. Sem propor a autonomia absoluta da ciência, cremos que deixar o problema no campo apenas político torna impossível algo que deveria ser evidente: poder discutir a própria evidência arqueológica que, além de todas as interpretações permeadas de uso político, pode ser julgada como mais ou menos bem argumentada cientificamente. Colocar a credibilidade da prova exclusivamente na capacidade convincente da política - obtida seja por coerção, seja por consenso - equivale não só a um reducionismo na compreensão da relação entre ciência e sociedade, como também a colocar-nos no plano de retóricas que não podem ser medidas. ${ }^{5}$ De outra forma, a falta de conhecimentos científi$\cos$, em especial na periferia, pode passar por ciência apenas por critérios políticos, o que reforça o caráter alienado da produção intelectual e sua dependência das relações de poder no interior da academia e na sociedade em geral.

O debate originado no WAC3, em Nova Delhi, relaciona-se a isso. Com efeito, neste encontro, o contexto extra-acadêmico irrompeu com força brutal, nas mãos dos conflitos da política da Índia, na última década. Nesse evento, diversas pressões levaram à proibição de debater-se a destruição da mesquita de Babri Masjid, em Ayodhya, ocorrida em 1992. Esta demolição havia sido uma demonstração do poder crescente dos grupos ligados ao BJP, partido que depois chegou ao governo e que insiste em uma identidade induísta para a Índia como um todo, em detrimento da diversidade cultural daquele país. O BJP conseguiu a adesão de muitos cidadãos e cooptou uma série de arqueólogos que definem sua prática intelectual em função de sua adesão ao partido nacionalista radical. Como parte dessa adesão, inclui-se a elaboração e a legitimação de uma retórica histórica e simbólica, que envolve tanto a idéia de uma essência social homogênea, perturbada pela "invasão" muçulmana, como o direito de destruir os testemunhos materiais desses "invaso-

(5) A respeito, cabe destacar que, em relação aos debates teóricos da arqueologia anglo-saxônica, também outras arqueologias européias aparecem como periféricas (cf. Härke 1998). res", a fim de recuperar uma suposta pureza étnica e religiosa, ariana, que antecedia a dominação semita. Pode-se lembrar que um dos pontos principais da plataforma política do BJP propõe a reconstrução do templo de Rama, que os "invasores muçulmanos" haviam destruído, séculos antes, para construir a mesquita. Os arqueólogos cooptados pelo BJP produziram as provas arqueológicas da existência de tal templo e, além disso, defenderam sua reconstrução. Qualquer dos grupos em conflito poderia argumentar que luta pelo direito a definir a identidade e a autonomia de seu país e, sem nenhuma dúvida, essa afirmação de qualquer das partes seria verdadeira e não pode ser resolvida apelando-se aos postulados do WAC. Ao situar o argumento de justificativa na luta política, é claro que o juízo sobre a verdade equivale a um compromisso - enunciado como um compromisso ético -, cuja característica principal é sua manifesta subjetividade.

O WAC3 de Nova Delhi abriu um debate em seu seio que, segundo pensamos, resulta de haver sempre navegado em um difícil equilíbrio entre o relativismo cultural e a pretensão em expressar uma abordagem universal e humanista (este o sentido de world archaeology). Enquanto a vontade relativista está representada pelos temas, a pretensão universal está inscrita nos supostos que implicam escorar-se em pautas comuns para todos os membros. A pauta consiste, neste caso, em reconhecer o direito do "outro", esse "outro cultural" excluído dos grandes discursos da modernidade. Isto se traduziu, assim, no apoio ao repatriamento ${ }^{6}$ e no respeito aos direitos das minorias e dos povos indígenas em recuperar seu passado ou a escrever sua História como meio de consolidar sua identidade, dois temas que, sem dúvida, se relacionam com o conflito de Ayodhya.

Outro elemento que a abordagem relativista, às vezes, desconhece é a violência com que se im-

(6) A respeito do repatriamento e a partir do lugar da instituição formuladora de prescrições de validade universal, WAC redigiu e aprovou um "Código de Ética Arqueológica", em relação ao tratamento de restos de esqueletos humanos (Podgorny e Miotti 1994). Neste momento, a crença religiosa foi introduzida na discussão. Na reunião da Dakota do Sul, em 1990, o seu respeito foi a base para a crítica à exposição de corpos e apetrechos funerários. As sessões eram precedidas por rezas ou orações de algum representante indígena presente. Por sua vez, a cerimônia de reenterramento, em Wounded Knee, foi realizada mediante orações e rituais de todas as religiões dos participantes, em respeito aos mortos. 
FUNARI, P.P.A.; NEVES, E.G.; PODGORNY, I. Introdução - a primeira reunião internacional de teoria arqueológica na América do Sul: questões e debates. Rev. do Museu de Arqueologia e Etnologia, São Paulo, Suplemento 3: 1-12, 1999.

põem os símbolos, da qual o conflito de Ayodhya foi testemunha e que acaba com a possibilidade de equidistância com relação às crenças. $\mathrm{O}$ processo de imposição de um determinado arco simbólico ligado a um projeto político nunca foi de outra maneira, tal como nos mostram os estudos sobre a invenção de tradições ou de arquétipos da nacionalidade (cf. Hobsbawn 1990, Hobsbawn e Ranger 1983). Contudo, em parte do discurso, isto levanta essa crítica a extremos pós-modernos, que consideram o passado como mera performance, pois toda interpretação seria válida, outorgando aos "outros" a possibilidade de crer e de usar os mecanismos legitimadores, os quais, paradoxalmente, a mentalidade pós-moderna já não reconhece como válidos. Assim, a aceitação do arianismo racista do BJP como "uma visão" sobre o passado, deixa de lado seu caráter totalitário e sua debilidade como prática científica verificável.

\section{O público na produção do conhecimento}

A institucionalização e a profissionalização das práticas científicas, no século XIX, implicou o processo de fechamento das disciplinas em seu próprio interior. Ilusória ou não, a possibilidade de campos autônomos de saber deixou de fora não apenas a relação direta com a política, como também a relação com o público que, no século XVIII, havia tido um status que, agora, custa reconhecer como científico. Os estudos na História das Ciências têm destacado que esse papel ia muito além do mero envolvimento com a ciência, pois a própria idéia de experimento - não confinado ao laboratório - era algo público. A ciência pode considerar-se como uma empresa imperial e, desta maneira, os centros coloniais adquirem um caráter subordinado, diante de uma experiência que ocorre nos herméticos laboratórios europeus. Neste contexto, o público excluído pode ser comparado aos cientistas excluídos, da periferia. Contudo, as práticas científicas não metropolitanas permitem falar de um intercâmbio negociado em um espaço em que os conceitos e instrumentos são ativamente despojados de seu sentido "original" para que o intercâmbio possa estabelecer-se.

No debate da arqueologia britânica, a conjugação do uso da internet e certas tentativas de devolver-se ao público um suposto lugar epistemológico na construção do conhecimento resultou, por exemplo, na polêmica entre Hodder e Hassan
(Hassan 1997, Hodder 1998). Ambos - Hodder sem o saber - lutam por modelos do século XVIII. As posições de Hodder levaram à intervenção epistemológica do público (entendido como realidade que circunda a prática arqueológica) na construção do relato arqueológico, por meio de uso da WEB. A difusão do uso da WEB pareceria ter criado um lugar democrático nas discussões e no uso dos recursos. Neste espaço, o tempo e o espaço da viagem, do translado, da carta e da biblioteca, assim como das discussões distantes, pareceriam também desaparecer. O que este debate esquece é que o "outro" seja científico, seja público, da periferia, ou o próprio público metropolitano, não está fora, mas dentro das próprias visões e idéias que parecem visíveis apenas graças a esse distanciamento.

\section{A reunião de Vitória}

Seguindo a tendência estabelecida, a partir da década de 80 , pelos fóruns dedicados à reflexão crítica sobre a Arqueologia, como os TAGs, o WAC e a Associação Brasileira de Antropologia uniram-se na iniciativa de propor, no quadro da 21'Reunião da ABA, em Vitória (ES, Brasil), de 6 a 9 de abril de 1998, a realização de uma Primeira Reunião Internacional de Teoria Arqueológica na América do Sul. A proposta começou a tomar forma em 1996, por iniciativa de Alejandro $\mathrm{Haber}^{7} \mathrm{e}$ Pedro Paulo Abreu Funari, ${ }^{8}$ quando se encontravam ambos em solo britânico para o trabalhos arqueológicos em Cambridge e Southampton, respectivamente, tendo recebido o incentivo de Ian Hodder e Peter Ucko. A partir destes primeiros entendimentos, e já com o apoio institucional do World Archaeological Congress, manifestado pelo secretário Julian Thomas, marcou-se para outubro de 1996 um encontro, na Argentina, para organizar uma proposta acadêmica mais detalhada. Em outubro, reuniões preparatórias foram realizadas na Universidade de Catamarca, que forneceu subsídios para que se pudesse efetuar reuniões de organização do

(7) Professor da Escuela de Arqueología, Universidad Nacional de Catamarca, Argentina.

(8) Estada financiada pelo World Archaeological Congress, em Janeiro de 1996. 
FUNARI, P.P.A.; NEVES, E.G.; PODGORNY, I. Introdução - a primeira reunião internacional de teoria arqueológica na América do Sul: questões e debates. Rev. do Museu de Arqueologia e Etnologia, São Paulo, Suplemento 3: 1-12, 1999.

evento, quando se definiu um programa inicial, uma comissão executiva ${ }^{9}$ e uma comissão científica de apoio. ${ }^{10}$

A organização do evento exigiu diversas outras reuniões iniciais, ${ }^{11}$ tendo-se ampliado o apoio institucional ${ }^{12}$ ao evento e à composição das comissões executivas ${ }^{13}$ e científicas. ${ }^{14}$ A Reunião teve o aporte financeiro de diversas instituições científicas e de fomento à pesquisa, ${ }^{15}$ tendo contado com duas conferências e vinte e cinco papers, agrupados em quatro grandes temas. As conferências, a cargo de Julian Thomas, sobre "A História e a política do WAC", e de Randall McGuire, sobre "Uma Arqueologia dos trabalhadores americanos", abriram o primeiro e o último dia do evento, respectivamente. A apresentação de Thomas permitiu que o público presente tomasse contato com a História do WAC, cujas políticas de reflexão crítica sobre o papel social e acadêmico do arqueólogo permitiram enquadrar todo o encontro. No primeiro dia, a discussão girou em torno de "Teoria e Método", com a apresentação de sete papers:

Julian Thomas, University of Southampton, Recontextualizing materiality and the social; Michael

(9) A primeira comissão executiva contava com Alejandro Haber, P.P.A Funari (representante sênior da América do Sul no Conselho Executivo do Congresso Mundial de Arquelogia), Irina Podgorny (representante júnior perante o mesmo Conselho) e Norberto Luiz Guarinello (Departamento de Historia, FFLCH-USP, Brasil).

(10) A primeira comissão científica era composta, além dos membros executivos, do Presidente do WAC, Bassey Andah, do Secretário, Julian Thomas, e Peter Ucko.

(11) Em particular, em Londres e Southampton, em fevereiro de 1997, com apoio do CNPq, quando se consolidaram os entendimentos com a direção do WAC e em maio do mesmo ano, quando, com apoio dos Departamentos de História da UNICAMP e da USP, a Profa. Podgorny participou de reuniões com Funari e Guarinello.

(12) A Sociedade de Arqueologia Brasileira, na gestão de Paulo Tadeu de Albuquerque e Sheila Mendonça, apoiou e divulgou o evento; a Associação de Antropologia Brasileira propôs a realização do encontro no quadro da reunião regular da ABA; o Fórum Interdisciplinar para o Avanço da Arqueologia, na gestão de Eduardo Góes Neves, associouse à proposta e a divulgou.

(13) Eduardo Góes Neves passou a integrar a comissão executiva.

(14) A Comissão Científica passou a contar, também, com a Presidente da ABA, Mariza Correa e com Haiganuch Sarian (MAE-USP, Brasil).

(15) World Archaeological Congress, CAPES, FAPESP, IFCH-UNICAMP e MAE-USP.
J. Heckenberger, Museu Nacional (UFRJ), "Hierarquia e economia política na Amazônia: a construção da diferença e da desigualdade em sociedades ameríndias"; André Prous, Museu de História Natural (UFMG), "As tradições rupestres: arqueofatos ou realidades?"; Gustavo Politis, Universidad de La Plata, "Cultura Material e crianças entre os Nukaks"; José Luis Lanata, Universidad de La Plata, The Archaeology of Hunters and Gatherers in South America: recent history; Erika Marion Robrahn-González (MAE-USP), "A cerâmica em estudos de interação e mudança cultural na região centro-oeste brasileira"; e Benjamin Alberti, University of Southampton, Gender Archaeology: a case study.

Confrontaram-se, nas discussões, as abordagens contextuais, ou pós-processuais, de Thomas e Alberti, que enfatizaram o caráter de construção discursiva da lide arqueológica, e enfoques mais ou menos informados no processualismo, de uma forma ou de outra representados pelos outros panelistas. Lanata e Heckenberger referiram-se, em suas palestras, a modelos genéricos explicativos, assim como Prous esboçou um análise crítica dos estudos sobre as pinturas rupestres. Politis gerou grande interesse e admiração pela pesquisa etno-arqueológica de campo e suas ilações sobre o papel das crianças foi particularmente instigante. RobrahnGonzáles relacionou o estudo da cerâmica com a dinâmica social no Brasil Central, tendo levado a troca de idéias com diversos colegas, em particular com Irmhild Wüst. A mediação de Irina Podgorny organizou o debate, que se prolongou pelo início da noite.

O segundo dia centrou-se no tema "Arqueologia e Etnicidade", mediado por Eduardo Góes Neves, tendo contado com seis apresentações:

Francisco Noelli, Universidade Estadual de Maringá, "Repensando os rótulos sobre os Jê do sul do Brasil: pelo compassamento entre algumas noções básicas da Arqueologia e da Etnologia"; Scott Allen, Universidade Federal de Alagoas/Brown University, "Etnicidade e Arqueologia Histórica do Quilombo dos Palmares"; Stephen Shennan, Insitute of Archaeology, Londres, Concepts of ethnicity in the past and present; Carlos Magno Guimarães (FAFICH-UFMG), "Arqueologia e grupos étnicos: os quilombos"; María Ximena Senatore, Universidad de Buenos Aires, Arqueología del contacto europeoamericano. Discusión teórica y modelos de análisis en áreas marginales; e Irmhild Wüst, Universidade 
FUNARI, P.P.A.; NEVES, E.G.; PODGORNY, I. Introdução - a primeira reunião internacional de teoria arqueológica na América do Sul: questões e debates. Rev. do Museu de Arqueologia e Etnologia, São Paulo, Suplemento 3: 1-12, 1999.

Federal do Goiás, "Continuidades e descontinuidades: Arqueologia e Etnoarqueologia no coração do território Bororo oriental, Mato Grosso"

A etnicidade foi tratada, pelos diversos expositores, a partir de diferentes ângulos, gerando debates entre os panelistas e entre estes e os outros participantes. Noelli desenvolveu uma crítica dos modelos vigentes na arqueologia brasileira em geral, e quanto ao sul do Brasil, em particular, propondo, em seu lugar, uma análise que tente integrar os dados arqueológicos àqueles históricos, etnográficos e lingüísticos. Os problemas de tal pretensão foram aventados por Funari, em particular no contexto das discussões mais recentes sobre Arqueologia e Etnicidade. Estas formaram o cerne do paper de Wüst, cujo endosso da literatura mais atualizada (e.g. Siân Jones) acabou gerando discussões diversas. Shennan, em sua apresentação, somou-se a Wüst ao demonstrar como a Etnicidade é antes construção complexa que busca traços de origem. Allen e Senatore, com estudos de casos específicos, juntaram-se àqueles que propugnam pela complexidade das relações étnicas e pelos decorrentes desafios de seu estudo a partir da cultura material. Talvez a apresentação mais controversa tenha sido a de Guimarães, sobre a identificação arqueológica de quilombos para fins de demarcação de terras. Diversos antropólogos presentes divergiram das propostas de Guimarães sobre a chamada "ressemantização" do conceito de quilombo, tal como proposto por um grupo de trabalho da ABA.

O terceiro dia foi organizado, por Funari, em torno da discussão da "Paisagem, cultura material e patrimônio", tendo contado com seis apresentações:

Andrés Zarankin, Universidad de Buenos Aires/UNICAMP, ${ }^{16}$ Arqueología de la Arquitectura: un modelo teórico metodológico para su abordaje; Cristina Bruno (MAE-USP), "A importância dos processos museológicos para a preservação do patrimônio"; Elizabete Tamanini, Museu Arqueológico de Sambaqui de Joinville/ UNICAMP, ${ }^{17}$ "Arqueologia e Educação: teoria e prática"; Eduardo Góes Neves (MAE-USP), "Mito, História e Arqueologia na Bacia do Alto Rio Negro, Amazônia"; Marisa Lazzari, Universidad de

(16) Doutorando da UNICAMP.

(17) Doutoranda da UNICAMP.
Buenos Aires, Objetos viajeros e imágines espaciales: relaciones de intercambio y la producción del espacio social; e Felix Acuto, Universidad de Buenos Aires, Paisages cambiantes: la ocupación Inka en el Valle del Calchaquí Norte, Argentina.

As discussões centraram-se, por um lado, nas apropriações da cultura material, objeto de estudo do arqueólogo, por parte da sociedade em geral. Bruno e Tamanini apresentaram reflexões sobre como o trabalho arqueológico envolve, necessariamente, considerações sobre a transformação destes artefatos em patrimônio, acadêmico e extra-acadêmico. Houve grande discussão a este respeito, pois muitos arqueólogos dissociam seu trabalho, propriamente arqueológico, da patrimonização da cultura material. Por outro lado, Zarankin, Neves, Lazzari e Acuto utilizaram-se de estudos de caso para apresentar propostas de uso da teoria arqueológica. Zarankin discutiu a relação entre os modelos arquitetônicos e a Arqueologia, enquanto, ainda no campo interdisciplinar, Neves relacionou História, Mito e Arqueologia. A paisagem foi tratada de forma original por Lazzari e Acuto, destacando-se a preocupação daquela com os movimentos dos objetos e deste último com a diacronia no assentamento humano.

O quarto dia começou com uma conferência de McGuire, uma muito oportuna introdução à mesa que se seguiria. Em sua apresentação, McGuire tratou dos excluídos da História dos Estados Unidos, os trabalhadores, e mostrou um projeto de pesquisa arqueológica dos vestígios de um grupo de trabalhadores em greve, no início do século. Destacou, ainda, a transformação dessas evidências em patrimônio e demonstrou, de forma clara, seu propósito de engajar a Arqueologia na luta pela liberdade e na rejeição de uma Arqueologia que, ao se querer neutra e ahistórica, mostra-se conservadora e pouco capaz de explicar sua própria prática e teoria. A mesa-redonda que se seguiu, sobre "Arqueologia latino-americana: teoria e História" mediada por Neves, mostrou-se particularmente fértil em suscitar debates e compôs-se de seis papers:

Bernd Fahmel Beyer, Instituto de Investigaciones Arqueológicas, UNAM, México, Academy and culture in Mesoamerica: two realities?; Cristiana Barreto, University of Pittsburgh, "A Arqueologia no Brasil e na América Latina"; Haiganuch Sarian (MAE-USP), "Arqueologia Clássica no Brasil: fronteiras e horizontes"; Irina Podgorny, Universidad de La Plata, The reception of New Archaeology in Argentina: boundaries, contexts and power; 
FUNARI. P.P.A.; NEVES, E.G.; PODGORNY, I. Introdução - a primeira reunião internacional de teoria arqueologica na América do Sul: questões e debates. Rev. do Museu de Arqueologia e Etnologia, São Paulo, Suplemento 3: 1-12, 1999.

Pedro Paulo A. Funari, UNICAMP, “A importância da teoria arqueológica internacional para a arqueologia brasileira"; e Randall MacGuire, Binghamton University, Radical theory in Anglo-American and Hispanic archaeology.

Todos os papers trataram da História da Arqueologia a partir de estudos de caso e pontos de vistas diferentes. Beyer, Podgorny e Funari ressaltaram, ao estudar a América Central, a Argentina e o Brasil, respectivamente, as relações entre o contexto histórico e as práticas e teorias arqueológicas. Barreto procurou contrapor-se a tais contextualizações, tratando dos avanços da Arqueologia no Brasil como desenvolvimentos no interior da ciência. Sarian, embora tenha tratado da Arqueologia Clássica, apenas um dos campos de investigação no Brasil, ressaltou os efeitos cientificamente destacáveis dessa área. McGuire forneceu uma visão ampla, contrapondo a arqueologia americana à hispano-americana, com destaque para a Arqueologia Social Latino-Americana. As discussões centraram-se no grau de autonomia da ciência arqueológica e nas suas relações com a sociedade abrangente.

Ao final, Neves e Funari mediaram uma plenária sobre o evento. Diversos participantes ressaltaram a importância e inovação de um encontro deste tipo, baseado na troca de idéias. Ressaltou-se que, em um contexto ainda marcado pelos conflitos, até mesmo de caráter pessoal, a apresentação de papers e sua discussão marcou uma nova etapa, em reuniões arqueológicas na América do Sul. Em seguida, foi enfatizada a importância da inserção da arqueologia sul-americana na arqueologia mundial. Surgiu a proposta de realizar-se o segundo encontro, tendo sido formada uma comissão provisória ${ }^{18}$ para encaminhar o evento, que está planejado para outubro ou novembro do ano 2000. A publicação dos papers foi sugerida e solicitou-se o envio dos textos. O público, além dos panelistas, compreendeu arqueólogos, antropólogos e outros interessados de diferentes instituições, em particular MAE-USP, UNICAMP, UFES, UFMG, MASJ, Universidade Estácio de Sá (RJ), UFRJ, Universidade Estadual de Blumenau e Museu Nacional. Tomaram parte estudiosos do Brasil, Argentina, México, Estados Unidos e Grã-Bretanha.

O evento foi avaliado positivamente e os textos começaram a chegar, já logo depois do encontro.

Em novembro de 1998, já com diversos textos recebidos, solicitou-se o apoio da FAPESP para a publicação do volume pelo Museu de Arqueologia e Etnologia da Universidade de São Paulo, tendose, novamente, recebido um parecer favorável.

Além dos papers apresentados em Vitória, alguns deles modificados para publicação, vários autores, que não puderam comparecer ao encontro, por diversos motivos, mas que haviam preparado trabalhos, acabaram contribuindo para este volume, como é o caso de Alejandro Haber, Margarita Díaz-Andreu, Hakan Karlsson e Charles E. Orser. Por outro lado, alguns participantes não enviaram seus textos a tempo.

\section{Agradecimentos}

Agradecemos a todos os que participaram do encontro em Vitória e a Fekri Hassan, Siân Jones, Peter Stone, Bruce Trigger e Peter Ucko. A responsibilidade pelas idéias, naturalmente, restringe-se aos autores. Mencionem-se, ainda, os apoios institucionais da FAPESP, ABA, IFCH/UNICAMP, MAE-USP. O apoio da Dra. Cíntia Ávila, do Departamento de Antropologia da UFES, foi fundamental para a realização do evento. Esse volume só veio à luz graças ao trabalho, paciência e olho crítico editorial de Maria Isabel D'Agostino Fleming. A ela, nossa gratidão. 
FUNARI, P.P.A.; NEVES, E.G.; PODGORNY, I. Introdução - a primeira reunião internacional de teoria arqueológica na América do Sul: questões e debates. Rev. do Museu de Arqueologia e Etnologia, São Paulo, Suplemento 3: 1-12, 1999.

\section{Referências bibliográficas}

BERNBECK, R.; POLLOCK, S.

1996 Ayodhya, Archaeology, and Identity. Current Anthropology, 37, Supplement: February: 138-142.

BERNBECK, R.; SOMMER, U.

1994 Politik, Mythos und Archäologie: der World Archaeological Congress 3 in New Delhi 1994 und Ayodhya. Etnographisch-Archäologische Zeitschrift, 35: 475-498.

BOURDIEU, P.

1984 Homo academicus. Stanford: Stanford University Press. 1988.

BROCHADO, J.

1984 An ecological model for the spread of pottery and agriculture into Eastern South América, Ph.D. Dissertation, University of Illinois.

COLLS, R.; DODD, P. (Eds.)

1986 Englishness, politics and culture 1880-1920. Londres: Croom Helm.

CRIADO BOADO; GÁNDARA, M.F.

1982 La vieja "Nueva Arqueología” En Teorías, métodos y técnicas en arqueología, reimpresiones del Boletín de Antropologia Americana, México.

CROSBY, A.

1986 Ecological Imperialism. The Biological Expansion of Europe, 900-1900. Cambridge: Cambridge University Press.

GÁNDARA, M.

1982 La vieja "Nueva Arqueología", en Teorías, métodos y técnicas em arqueología, reimpresiones del Boletin de Antropología Americana, México.

GILMAN GUILLÉN, A.

1988 Enfoques teóricos en la arqueología de los ochenta. Revista de Occidente, 81: 47-61 (traducción de Consuelo Vázquez de Parga) Madrid.

GILMAN GUILLÉN, A.; HÄRKE, H.

1998 Archaeologists and migrations: a problem of attitude? Current Anthropology, 39 (1): 19-46.

HASSAN, F.

1997 Comments on Hodder's 'Reflexive excavation methods' Antiquity, 71: 1020-25.

HECKENBERGER, M.; NEVES, E.; PETERSEN, J.

1998 De onde surgem os modelos? As origens e expansões Tupi na Amazônia Central. Revista de Antropologia, 41 (1): 69-96.

HOBSBAWN, E.

1990 Nations and Nationalism since 1780; Programme, Myth, Reality. Canto: Cambridge University Press.

HOBSBAWN, E.; RANGER, T. (Eds.)

1983 The Invention of Tradition. Cambridge: Cambridge University Press.

\section{HODDER, I.}

1986 Reading the past; current approaches to interpretation in archaeology. Cambridge: Cambridge University Press.
1998 Whose rationality? A response to Fekri Hassan. Antiquity, 72: 213-217.

HODDER, I.; PARKER PEARSON, M.; PECK, N.; STONE, P.

1995 Archaeology, knowledge and society: surveys in Britain. M.s.

JONES, $S$.

1997 The Archaeology of Ethnicity, Constructing identity in the past and present. Londres: Routledge.

KOHL, Ph.

1981 Materialist approaches in prehistory. Ann. Rev. Anthropol., 10: 89-118.

1985 Symbolic cognitive archaeology: a new loss of innocence. Dialectical Anthropology, 9: 105-117.

1988 Review of "Academic Freedom and Apartheid: The story of the World Archaeological Congress. Peter Ucko. London: Duckworth, 1987", Academe, July-August, 1988.

KOHL. Ph.; FAWCETT, C. (Eds.)

1995 Nationalism, politics and the practice of archaeology. Cambridge: Cambridge University Press.

PODGORNY, I.

1994 Arqueología y educación. La presentación de los pueblos indígenas en la educación argentina. Tesis de doctoral presentada en 1994 en la Facultad de Ciencias Naturales y Museo de la Universidad Nacional de la Plata.

1996 El tercer Congreso Arqueológico Mundial en Nueva Delhi y los límites de la ingenuidad postmoderna. Relaciones de la Sociedad Argentina de Antropologia, 21: 103-117. Buenos Aires.

The past is a fragment of the Berlin wall. $\mathbf{K}$. Smarz (Ed.) Childworth experience. University of Southampton. (no prelo).

PODGORNY, I.; MIOTTI, L.

1994 El pasado como campo de batalla. Ciencia Hoy, Buenos Aires, 5 (25): 16-19.

PROUS, A.

1992 Arqueologia Brasileira. Brasília: Editora da UnB.

RAO, N.

1995 Politics and the World Archaeological Congress - 3. Trabajos de Prehistoria, Madrid, Centro de Estudios Históricos, CSIC, 52 (1): 5-11.

RONAYNE, M.

1995 WAC 3-Involvement and Identities. WAC news, 3 (1): i-ii

RUIZ ZAPATERO, G.

1993 La organización de la arqueología en España. M.I. Martínez Navarrete (Coord.) Teoría y práctica de la prehistoria: perspectivas desde los extremos de Europa, reunión Hispano-rusa de prehistoriadores (1990), CSIC-Universidad de Cantabria: 45-71. 
FUNARI, P.P.A.; NEVES, E.G.; PODGORNY, I. Introdução - a primeira reunião internacional de teoria arqueológica na América do Sul: questões e debates. Rev. do Museu de Arqueologia e Etnologia, São Paulo, Suplemento 3: 1-12, 1999.

SHANKS, M.; TILLEY, C.

1987 Re-constructing archaeology Theory and Practice. Cambridge: Cambridge University Press.

STONE, $P$.

1986 Are the public really interested? C. Dobinson; R. Gilchrist (Eds.) Archaeology politics and the public, Papers given to the Young Archaeologists' Conference in York, 1984. York, York University Archaeological Publications: 14-21.

TIERNEY, M.

1995 WAC 3 and the role of archaeologists as intellectuals, WAC news, 3(1): ii-iii.

TILLEY, Ch.

1991 Material culture and text. The art of ambiguity. New York: Routledge.

TRIGGER, B.G.

1980 Archaeology and the image of the American Indian. American Antiquity, 45: 662-676.
1989 A History of archaeological thought. Cambridge: Cambridge University Press.

UCKO, P.

1986 Political uses of archaeology. C. Dobinson; R. Gilchrist (Eds.) Archaeology, politics and the public, Papers given to the Young Archaeologists' Conference in York, 1984. York, York University Archaeological Publications: 45-49.

1987 Academic freedom and apartheid. The story of the World Archaeological Congress. Duckworth: Londres.

WÜST, I.

1990 Continuidade e Mudança: para uma interpretação dos grupos pré-coloniais na bacia do rio Vermelho, Mato Grosso, Tese de Doutoramento, FFLCH, Universidade de São Paulo. 